\title{
RURBANIDADE NO "BRASIL PROFUNDO". ANÁLISE DE SIMILITUDE EM ENTREVISTAS COM JOVENS GAÚCHOS
}

\author{
Rurbanity in "Deep Brazil": similitude analysis in interviews with young people \\ in Rio Grande do Sul
}

\begin{abstract}
Rurbanidad en "Brasil Profundo": análisis de similitud en entrevistas con jóvenes del Rio Grande do Sul
\end{abstract}

\author{
Nilda Jacks \\ Professora titular. PPGCOM/UFRGS. Bolsista PQ/CNPq \\ njacks@terra.com.br \\ Mariangela Machado Toaldo \\ Professora Associada da Fabico/UFRGS \\ mariangela.toaldo@ufrgs.br \\ Danillo dos Santos Lima \\ Formando em jornalismo. Fabico/UFRGS. Bolsista IC \\ danillo.lima1@gmail.com
}

\begin{abstract}
Resumo
Apresentamos um estudo sobre jovens (18 a 24 anos) moradores de quatro cidades do interior gaúcho: Itati, Pedras Altas, Porto Vera Cruz e Turuçu. O artigo é parte de uma pesquisa de âmbito nacional chamada Jovem Brasileiro e Práticas Midiáticas em Tempo de Convergência: $o$ "Brasil Profundo" (PROCAD/CAPES). A intenção é compreender a relação dos jovens com as tecnologias digitais em um contexto rurbano - confluência das características comuns às áreas rurais presentes nas áreas urbanas e vice-versa. Realizamos entrevistas estruturadas e processamos os resultados com o auxílio do programa IRAMUTEQ. Através da análise de similitude, verificamos as coocorrências entre as palavras, e os resultados indicam o destaque do uso de redes sociais nas quatro cidades, com especificidades de acordo com o contexto local e suas atividades profissionais - comércio, serviços, agricultura e pesca.
\end{abstract}

Palavras-chave: Rurbanidade. Jovem. Convergência Midiática.

\begin{abstract}
We present a study about young people (18 to 24 years old) from four cities in the interior of Rio Grande do Sul: Itati, Pedras Altas, Porto Vera Cruz and Turuçu. The article is part of a nationwide research called Jovem Brasileiro e Práticas Midiáticas em Tempo de Convergência: $o$ "Brasil Profundo" (PROCAD/CAPES). The intention is to understand the relationship of young people with digital technologies in a rurban context - the common characteristics of rural areas present in urban areas and vice versa. We did structured interviews and process the results in IRAMUTEQ software. Through the similitude analysis, we verified the co-occurrences
\end{abstract}


between words, and the results indicate the strong use of social media in the four cities, with specificities according to the local context and their professional activities - commerce, services, agriculture and fishing.

Key words: Rurbanity. Young people. Media Convergence.

\section{Resumen}

Presentamos un estudio de jóvenes (18 a 24 años) de cuatro ciudades del interior del Rio Grande do Sul: Itati, Pedras Altas, Porto Vera Cruz y Turuçu. El artículo es parte de una investigación de ámbito nacional denominada Jovem Brasileiro e Práticas Midiáticas em Tempo de Convergência: o "Brasil Profundo" (PROCAD/CAPES). La intención es comprender la relación de los jóvenes con las tecnologías digitales en un contexto rurbano - las características comunes de las áreas rurales presentes en las áreas urbanas y viceversa. Hicimos entrevistas estructuradas y procesamos los resultados en el programa IRAMUTEQ. A través del análisis de similitud, verificamos las co-ocurrencias entre palabras, y los resultados indican el fuerte uso de las redes sociales en las cuatro ciudades, con especificidades de acuerdo al contexto local y sus actividades profesionales - comercio, servicios, agricultura y pesca.

Palabras clave: Rurbanidad. Joven. Convergencia midiática.

\section{INTRODUÇÃO}

Esse artigo é fruto da análise de dados parciais da pesquisa Jovem Brasileiro e Práticas Midiáticas em Tempo de Convergência: o "Brasil Profundo" ${ }^{1}$, realizada no âmbito do Programa Nacional de Cooperação Acadêmica (PROCAD)², promovido pela Coordenação de Aperfeiçoamento de Pessoal de Nível Superior (CAPES). Trata-se de conhecer, entre segmentos de jovens que vivem no interior do Brasil, sua relação com as tecnologias digitais e as redes sociais. $\mathrm{O}$ caso aqui apresentado refere-se aos jovens pesquisados no interior do Rio Grande do Sul.

Partimos de uma noção múltipla de juventude, a qual propõe que "ser jovem é um leque de modalidades culturais que se desenvolvem com a interação das probabilidades parciais dispostas pela classe, pelo gênero, pela idade, pela memória incorporada e pelas instituições" (Margulis \& Urresti, 2008, p. 29) ${ }^{3}$. Ou seja, entre as condições acima enumeradas é necessário considerar que são configuradas por diferentes cenários socioculturais, como os urbanos e rurais, por exemplo, mas que não se esgotam neles.

\footnotetext{
${ }^{1}$ Para outros resultados parciais, ver Jacks, Toaldo, \& Marques, 2017; Jacks et al., 2017; Jacks, Toaldo, Miranda, \& Monteiro, 2017; Marques, Jacks, \& Toaldo, 2017; Marques, J. A., Toaldo, M. M., \& Jacks, N. (2017-2018); Toaldo, Jacks, \& Marques, 2018; Jacks, N., Toaldo, M., \& Marques, 2020; JACKS, 2020a;

2 O Programa de Pós-Graduação em Comunicação da Universidade Federal do Rio Grande do Sul lidera o projeto, que é composto ainda pelos Programas de Pós-Graduação em Comunicação da Universidade Federal de Sergipe e do Pará.

${ }^{3}$ Os autores a concebem como uma situação existencial singular que não se dá de forma igual com todos seus integrantes, pois depende da condição constituída pelos contextos históricos e culturais.
} 
Como trabalhamos com jovens de pequenos municípios afastados dos grandes centros urbanos e muito próximos da zona rural $^{4}$, adotamos a noção de rurbano (Cimadevilla \& Carniglia, 2009; Cimadevilla, 2010) para melhor compreender seus contextos e situações vivenciais. A noção remete-se a características comuns às áreas rurais presentes nas áreas urbanas e vice-versa, as quais oferecem peculiaridades importantes para compreender a cultura juvenil. A relação entre esses dois âmbitos produz algo diferente e, ao mesmo tempo, comum aos dois, propiciando intersecções que pautam as experiências e vivências, as quais podem resultar em sociabilidades e consumos culturais específicos, o que inclui os midiáticos e digitais (JACKS, 2020).

Contextos rurbanos compõem parte importante do "Brasil Profundo", expressão tomada de empréstimo da fortuna teórica mexicana para adentrar no interior do país na tentativa de conhecer um pouco da realidade dos jovens que vivem em regiões mais afastadas dos centros metropolitanos. "Brasil Profundo" faz analogia ao clássico "México Profundo" (Batalla, 1989), de autoria do antropólogo Bonfil Batalla, o qual analisa a civilização mexicana composta pela cultura indígena e a ocidental ${ }^{5}$.

Aqui são analisadas as entrevistas de tipo estruturada realizadas com jovens de ambos os sexos, moradores em quatro cidades do interior do Rio Grande do Sul, na faixa de 18 a 24 anos. $\mathrm{O}$ roteiro ${ }^{6}$ era composto por dez perguntas abertas relativas aos dados de identificação, atividades desenvolvidas no dia -a- dia e nos finais de semana, usos das redes sociais, da internet e de dispositivos tecnológicos para efetuar a conexão, consumo cultural e midiático, convívio familiar e de amizades nas redes sociais, assim como no trabalho e no estudo, além das fontes de informação nas plataformas digitais.

Os dados das entrevistas foram processados ${ }^{7}$ pelo software IRAMUTEQ ${ }^{8}$ (Interface de $\mathrm{R}^{9}$ pour les Analyses Multidimensionnelles de Textes et de Questionnaires), o qual é gratuito e

\footnotetext{
${ }^{4}$ Para o IBGE trata-se de rural adjacente, ou seja, município cuja "distância for igual ou inferior à média nacional em relação a pelo menos um dos centros REGIC, que corresponde às "Regiões de Influência das Cidades", classificadas "hierarquicamente a partir da intensidade das ligações entre os municípios" (IBGE, 2018, p. 54).

5 Para o autor "profundo" é o México composto pela civilização pré-colombiana, ou mesoamericana, e o "imaginário" é o fundado na civilização ocidental, o qual sustenta o modelo de desenvolvimento atual, que sobrepõe outras formas possíveis de desenvolvimento.

${ }^{6}$ Quatro equipes foram a campo quase simultaneamente no período de 15 a 21 de agosto de 2017 . Uma delas viajou para as quatro cidades para acompanhar toda a expedição, percorrendo mais de dois mil quilômetros, sendo responsável também pela cidade de Porto Vera Cruz.

${ }^{7}$ Devido à sobreposição de termos na representação gráfica foram retirados os vícios de linguagem e as palavras frequência pequena.

${ }^{8}$ Desenvolvido por Pierre Ratinaud servindo para analisar três dimensões do objeto: corpus (total do material), texto (cada unidade) e segmentos (parte dos textos) (Camargo, Justo, 2013).

${ }^{9}$ Ancora-se no ambiente estatístico do software R, "uma plataforma de análise estatística com ferramentas gráficas muito avançadas, que é uma referência na análise estatística” (MAS, 2018, p.7, tradução nossa)
} 
desenvolvido sob a lógica do open source. Ele permite a realização de análises gerais de textos, sendo "capaz de trazer informações lexográficas, que também incluem estatísticas básicas, como frequência e quantidade de palavras, e outras funções mais avançadas, como Análise Fatorial de Correspondência (AFC), Classificação Hierárquica Descendente (CHD), Análise de Similitude e Nuvem de Palavras" (SILVA, et al, 2018: 10).

O IRAMUTEQ “tem por finalidade descobrir a informação essencial contida num texto, através de análise estatística textual" (Camargo, 2005 Apud Moura, 2015: 169), sem perder seus aspectos qualitativos. As análises são de cunho quali-quanti, "tendo em vista que analisam palavras utilizadas no discurso, bem como quantitativamente, pois são analisadas pela frequência e pelo método estatístico inferencial do Qui-Quadrado ${ }^{10 "}$ (SILVA, ENUMO, 2017: 581). No caso das análises de similitude ${ }^{11}$, elas possibilitam a verificação de coocorrências entre palavras, e seu resultado traz indicações da conexidade entre elas, auxiliando na identificação da estrutura do campo representacional (Moura, 2015). Além da interconexão, é possível visualizar o nível de relação entre elas, que podem ser mais fortes ou mais fracos. O programa facilita a classificação dos termos dos discursos em categorias, "considerando a frequência das palavras utilizadas, bem como em qual contexto elas se apresentam, o nível de relação entre elas, mensurado pelo Qui-Quadrado e nível de significância, além de apresentar materiais gráficos que facilitam a visualização do conteúdo analisado" (SILVA, ENUMO, 2017:591).

\section{ITATI, PEDRAS ALTAS, PORTO VERA CRUZ E TURUÇU: RURBANIDADE NO "BRASIL PROFUNDO"}

Os contextos rurbanos estudados são constituídos pelas cidades de Itati - localizada na região nordeste do estado; Pedras Altas - na região sudeste, fronteira com o Uruguai; Porto Vera Cruz - no noroeste, às margens do Rio Uruguai - fronteira fluvial com Argentina e Turuçu à sudoeste ${ }^{12}$.

10 "O teste de associação qui-quadrado é o teste estatístico mais antigo e um dos mais usados em pesquisa social. É um método que permite testar a significância da associação entre duas variáveis qualitativas” (BARBETTA, 2002, p.246)

${ }^{11}$ As análises podem ser temáticas e monotemáticas. Também é possível realizar Classificação Hierárquica Descendente (CHD), sendo possível e desejável conjugar ambas.

12 Em relação a Porto Alegre, Itati dista 157,6 km, percorrido em cerca de 1:50h; Porto Vera Cruz a 539,8 km, com percurso de $7 \mathrm{~h}$; Pedras Altas a 394,4km, percorridos em 5h14min; Turuçu a 212,3km, levando 2h40min de viagem. 
Itati tem população de 2.584 habitantes, $75 \%$ dos quais vivendo na zona rural. Do total de habitantes, 13,4\% têm entre 15 a 24 anos, distribuídos em 190 homens e 157 mulheres (IBGE, 2010). Pedras Altas tem população de 2.212 habitantes, 66\% dos quais vivendo na zona rural (IBGE, 2017). 338 estão na faixa entre 15 e 24 anos (IBGE, 2010), ou seja, 16\% da população é jovem. Deste total de jovens, $52 \%$ são homens e $48 \%$ são mulheres. Porto Vera Cruz, cuja população é de 1.676 habitantes (IBGE, 2010), 1412 vivendo na zona rural (IBGE, 2017). Cerca de $11 \%$ têm entre 15 e 24 anos, ou seja, somente 184 pessoas, 50,54\% masculinos e 49,46\% feminino. Turuçu com uma população de 3.522 habitantes, tem 2035 vivendo na área rural (IBGE, 2017). Do total, em torno de 536 estão na faixa etária de 15 a 24 anos, aproximadamente $15,21 \%$ da população, 272 são masculinos e 264 são femininos (IBGE, 2010).

\subsection{Destaque para o âmbito doméstico: jovens agricultores de Itati}

A análise de similitude (figura 1, abaixo) apresenta indicações de conexidade entre os termos ficar, casa, dia, celular, facebook, uso, whats e internet nas falas dos jovens, assim como a recorrência desses termos indicada pelo tamanho da fonte.

Há centralidade do termo ficar na representação gráfica e uma vinculação forte com o termo casa. Estas palavras pertencem a dois núcleos centrais no diagrama, formados a partir das nuvens $\mathbf{D}$ e $\mathbf{C}$. A relação entre esses conjuntos revela, para além da junção que gera a frase "ficar [em] casa", que esta é uma vinculação significativa, pela densidade da linha que os conecta. Pode-se inferir que ficar em casa é uma condição central para os jovens, onde realizam as tarefas diárias e a sociabilidade familiar, representada pelos termos pai, mãe, irmão e marido, com quem compartilham seu cotidiano.

As palavras whats e face, na nuvem $\mathbf{D}$, podem indicar que exercem papel mediador entre as pessoas que habitam o mesmo espaço e que é uma das práticas desenvolvidas no âmbito doméstico para falar com outras pessoas. 


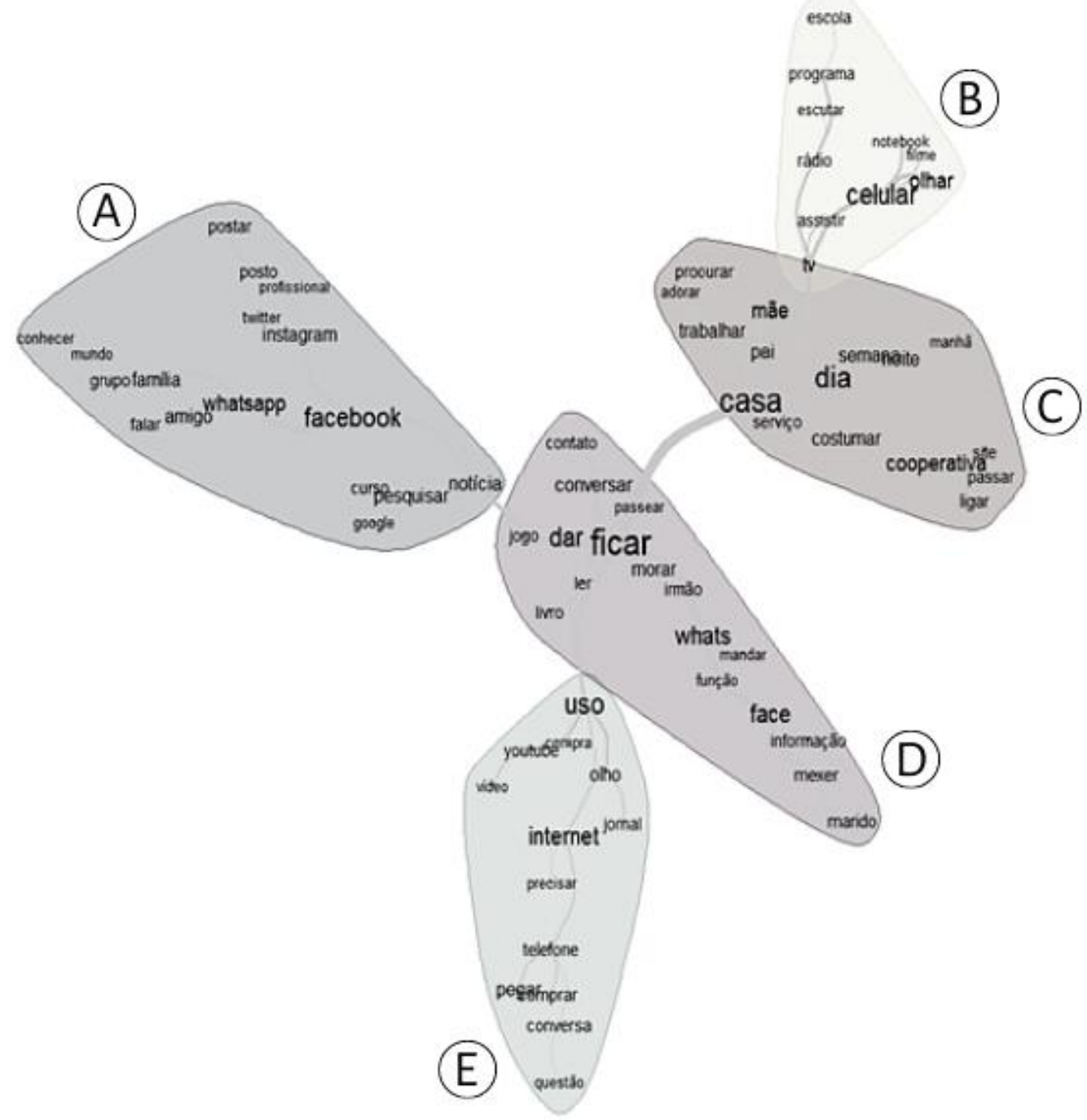

Figura 1: Análise de similitude: jovens de Itati

Fonte: Elaborado pelos autores

O agrupamento D está relacionado às atividades cotidianas - ficar, morar, conversar, passear-com algumas referências às pessoas e redes envolvidas - irmão, marido, whats e face. O agrupamento $\mathbf{C}$ apresenta marcadores de temporalidade, espaço e rotina, como indicam os termos casa, dia, semana, manhã, trabalhar e serviço. Este agrupamento aborda também a relação com o trabalho dos jovens, indicado pela representação da relação textual entre as palavras serviço, costumar e cooperativa. 
Por outro lado, a palavra casa se conecta com $t v$, numa intersecção entre a nuvem $\mathbf{C}$ e a B. A partir dessa vinculação se estrutura o conjunto de palavras da nuvem $\mathbf{B}$, como celular, olhar, rádio e escutar, que dizem respeito tanto aos dispositivos quanto às ações associadas a eles. As linhas que permeiam os agrupamentos $\mathbf{B}$ e $\mathbf{C}$ demonstram que as práticas de assistir televisão, olhar o celular e escutar rádio estão diretamente relacionadas com a palavra casa, de onde se infere que é o ambiente onde os jovens as realizam.

Assim como o conjunto $\mathbf{B}$, o $\mathbf{E}$ está relacionado ao uso (palavra em destaque) de tecnologias de comunicação, expresso pelos termos internet, youtube, telefone e jornal, porém não necessariamente ligado ao ambiente domiciliar, evidenciado pelo afastamento do agrupamento $\mathbf{C}$ identificado ao espaço doméstico. Vale destacar que a palavra telefone, interligada aos termos pegar, comprar, conversa, indica a importância do aparelho como meio que auxilia as relações profissionais.

O agrupamento $\mathbf{A}$ apresenta os termos especificamente relacionados ao uso de redes sociais, como indicam as palavras facebook, whatsapp e instagram. Segundo o tamanho dos termos facebook e whatsapp, pode-se deduzir que essas duas redes são mais recorrentes na fala dos jovens do que o instagram, podendo indicar que são mais utilizadas. A análise das linhas que vinculam as palavras aponta que o Facebook e o WhatsApp são utilizados principalmente na relação com a família e com amigos, e, em menor intensidade, para busca de notícias. No âmbito do trabalho, os termos instagram e facebook aparecem próximos às palavras profissional, posto e postar, indicando serem as redes mais usadas para fins profissionais. A palavra notícia está relacionada aos termos facebook, pesquisar, grupo e google, portanto podese dizer que a busca por conteúdo noticioso se dá através de pesquisas no buscador do Google e de postagens do Facebook.

Através da representação gráfica (figura 1), pode-se perceber espacialmente a proximidade entre os conjuntos $\mathbf{E}, \mathbf{A}$ e o $\mathbf{D}$, significando a afinidade entre as temáticas, as quais envolvem tecnologias que têm relação com a internet, utilizada fora do ambiente doméstico. Percebe-se que, durante a semana, o trabalho ocupa centralidade entre as atividades dos jovens entrevistados, o qual é desenvolvido na cooperativa ${ }^{13}$, pois é ela que concentra as atividades laborais dos jovens agricultores.

${ }^{13}$ COOMAFITT (Cooperativa Mista de Agricultores Familiares de Itati, Terra de Areia e Três Forquilhas) promove a comercialização dos alimentos produzidos por agricultores familiares. É uma opção de trabalho para os jovens da cidade de Itati. 
Quanto ao contexto doméstico, tanto no intervalo das atividades quanto nos momentos de lazer, os jovens compartilham com seus familiares. Ou seja, a residência é o lugar que perpassa a vida cotidiana deles. Quando estão em casa, utilizam os meios tradicionais - rádio, tv , e digitais - celular e notebook - de forma geral, com destaque para o uso do celular, que pode ser o meio de acesso aos demais.

\subsection{Centralidade do grupo familiar: jovens quilombolas de Pedras Altas}

A análise de similitude (figura 2, abaixo) apresenta forte conexidade entre os termos grupo, família, whatsapp, falar, olhar, celular, dia e casa, os de maior destaque, o que indica que foram os de maior recorrência nas falas dos jovens.

A centralidade dos conjuntos de associação $\mathbf{B}$ e $\mathbf{E}$, em que os termos remetem ao uso de redes sociais, demonstra sua importância para os entrevistados. O B, relativo ao nome das redes e práticas relacionadas a elas, é indicado pelos termos whatsapp, facebook e mensagem, postar, respectivamente. Já o $\mathbf{E}$ permite inferir sobre os usos específicos do WhatsApp, como vender e estudar, a forma de interação (grupo) e quem interage no aplicativo, indicado pelos termos família e amigo. Além disso, a ligação desses dois termos é representada por uma linha espessa, demonstrando a forte relação entre esses núcleos de sociabilidade.

Os grupos de WhatsApp relacionados à família representam o uso mais expressivo dessa função do aplicativo, evidenciado tanto pelo tamanho da fonte das palavras quanto pela força de ligação direta com o termo grupo. Por outro lado, a proximidade do termo estudar à palavra grupo, indica sua existência para finalidades escolares dos jovens, possivelmente formado por colegas da escola ou universidade. Percebe-se também a proximidade do termo vender à palavra família que aponta para o uso do WhatsApp para finalidades profissionais desse grupo social. 


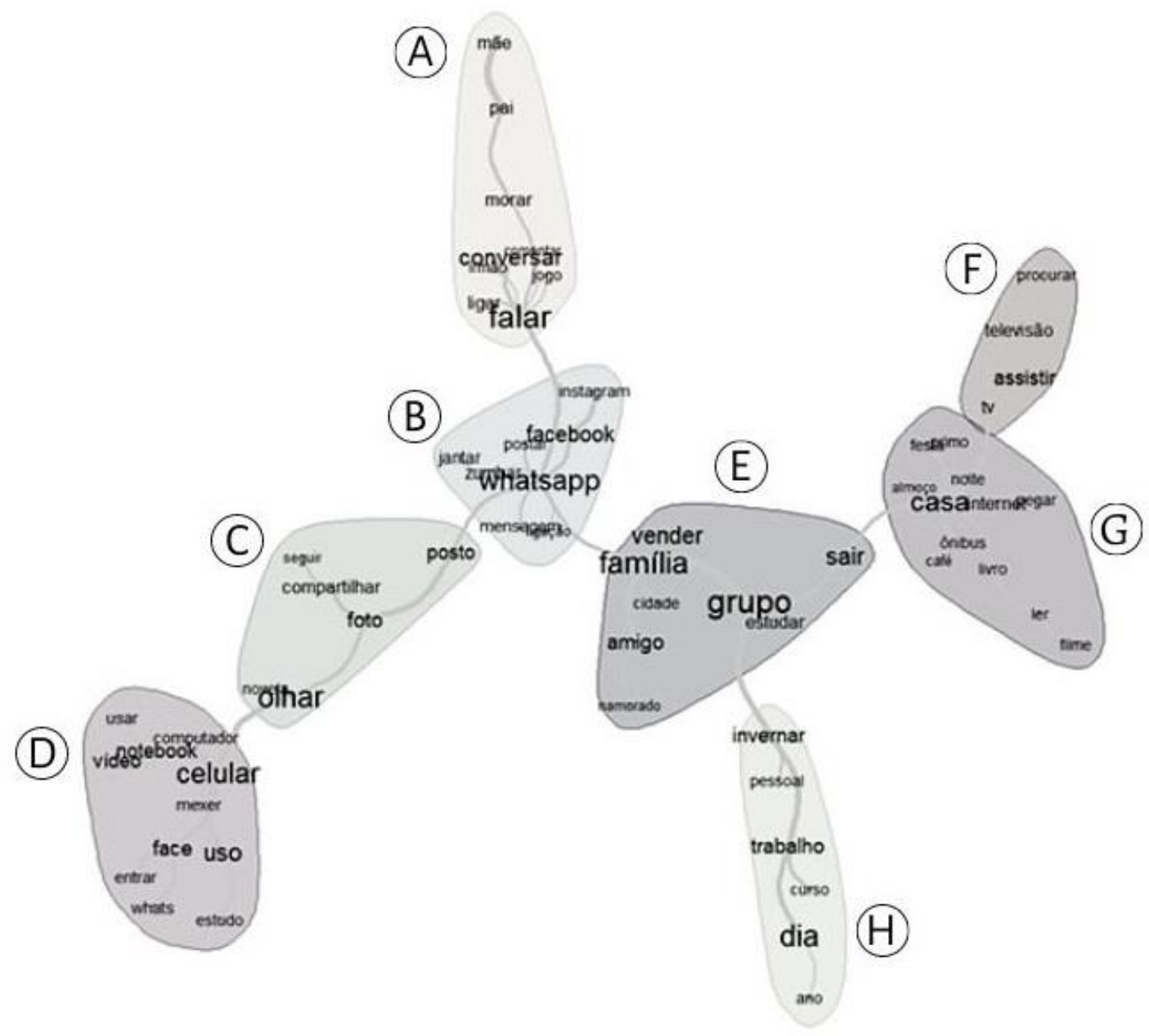

Figura 2: Análise de similitude: jovens de Pedras Altas

Fonte: Elaborado pelos autores

O conjunto $\mathbf{G}$ está amplamente relacionado às atividades domésticas, como indicado pelos termos casa, almoço e café. Outros termos dizem respeito ao cotidiano, como ônibus e noite, sendo este último a intersecção com o conjunto $\mathbf{F}$ através das palavras $t v$, assistir e procurar, apontando para as práticas midiáticas tradicionais. Seguindo o fluxo das linhas, que relaciona essas duas esferas, pode-se afirmar que a prática de assistir televisão se dá em casa, à noite. Compreende-se, ainda, que casa também é um lugar onde os jovens acessam internet e que as palavras livro, ler e filme, da mesma maneira relacionadas ao termo, indicam as atividades culturais e de lazer dos jovens no ambiente doméstico.

Por outro lado, em termos de configuração, percebe-se a formação de dois núcleos centrais que expressam a segmentação de temáticas na fala dos entrevistados. Próximo do núcleo encabeçado pela nuvem $\mathbf{E}$, a $\mathbf{H}$ apresenta forte ligação entre os termos invernar, trabalho 
e dia, sendo esta última palavra a mais expressiva nas falas, revelado pelo tamanho da fonte na representação gráfica. Em virtude dela estar ligada ao termo grupo do conjunto E, é possível interpretar que os termos do núcleo $\mathbf{H}$ estão relacionados em geral às conversações nos grupos de WhatsApp, com família, amigos, colegas de escola e de trabalho, se referem a temas profissionais, estudantis e pessoais, e que é uma atividade diurna.

O conjunto A, parte do outro núcleo de nuvens, destaca os termos falar e conversar como os mais expressivos. Esta nuvem está conectada à $\mathbf{B}$, por uma ramificação que leva aos termos whatsapp e facebook, o que indica que são redes usadas com a família, em especial o pai e a mãe, por aparecerem destacados no conjunto $\mathbf{A}$.

No mesmo conjunto, a nuvem $\mathbf{C}$ abarca termos que estão relacionados tanto ao Whatsapp quanto ao celular, respectivamente localizados no agrupamento B e D. A ligação do termo celular (nuvem D) com olhar (nuvem C) exprime a ação do jovem quanto ao uso constante do dispositivo. Da mesma forma, os termos seguir, compartilhar, foto e posto - este último ligado ao whatsapp (nuvem B) - demonstram as formas de uso das tecnologias.

A nuvem D aglutina as tecnologias utilizadas para acessar as redes sociais e os usos desenvolvidos nelas, respectivamente através dos termos celular, notebook, computador e mexer, uso. A linha que provém desses termos, ligando-os com os presentes na nuvem $\mathbf{C}$, comprova a relação existente entre tais tecnologias e seus usos.

A maior proximidade entre os conjuntos $\mathbf{D}, \mathbf{C}$ e $\mathbf{B}$ revela vinculação mais forte entre os assuntos identificados pelos termos que se conectam, os quais descrevem as práticas e tecnologias relacionadas ao celular. Ao mesmo tempo, a ligação desse conjunto àqueles configurados pelo $\mathbf{F}$ e $\mathbf{G}$ exprimem, através dos termos grupo (nuvem $\mathbf{G}$ ), que a temática domiciliar e do cotidiano também estão presentes.

Através dessa representação gráfica (figura 2), observa-se que, em geral, os jovens de Pedras Altas utilizam o celular com o propósito de se comunicarem principalmente com a família, secundariamente com os amigos e colegas, para agilizar atividades de negócios, de estudos e para socialização. A centralidade do WhatsApp na representação expõe a importância do aplicativo como a principal tecnologia para comunicação. Em casa, o consumo midiático que mais se ressalta é a prática de assistir televisão. 


\subsection{Sociabilidade mediada pelos grupos: jovens pescadores de Porto Vera Cruz}

$\mathrm{Na}$ análise de similitude (figura 3, abaixo) identifica-se a conexidade entre os termos mais evidenciados grupo, dia, tarde, sair, casa, domingo, trabalho, amigo, ver, conversar e notícia. Espacialmente, as nuvens mais à esquerda da figura estão em maioria apresentando temas relacionados ao uso das tecnologias, e os grupos à direita se mostram relacionados ao cotidiano e atividades domiciliares.

Destacam-se os termos grupo e dia devido à recorrência nas falas dos jovens, expresso pelo tamanho da fonte e também pela espessura da linha que os liga, que se estende à direita com tarde, sair e casa, na nuvem F. Isso revela marcadores de rotina e atividades relacionadas. No que se refere à tarde, identificam-se períodos dedicados ao estudo, a sair e às rotinas domiciliares, representadas a partir do termo casa. O movimento que se refere ao ato de sair está relacionado com ir à feira. Já o termo casa se conecta às palavras ligar, tv e vender, demonstrando atividades domiciliares relacionadas às práticas midiáticas e profissionais.

À direita, na nuvem G, os termos se relacionam aos fins de semana, como em domingo, sábado e trabalho - no caso deste termo, diz respeito à folga do fim de semana. Em relação à nuvem E, a palavra dia prepondera como a aglutinadora dos demais termos do conjunto. As associações do agrupamento remetem à rotina dos jovens relacionada ao trabalho, com enfoque nas marcações temporais, como se verifica nos termos dormir, noite e trabalhar. A relação familiar cotidiana é representada no conjunto através da conexão dos termos mãe e pai. A ligação entre rio e rede, que se conecta ao dia, demonstra a atividade de trabalho realizada pelos jovens, que são pescadores. 


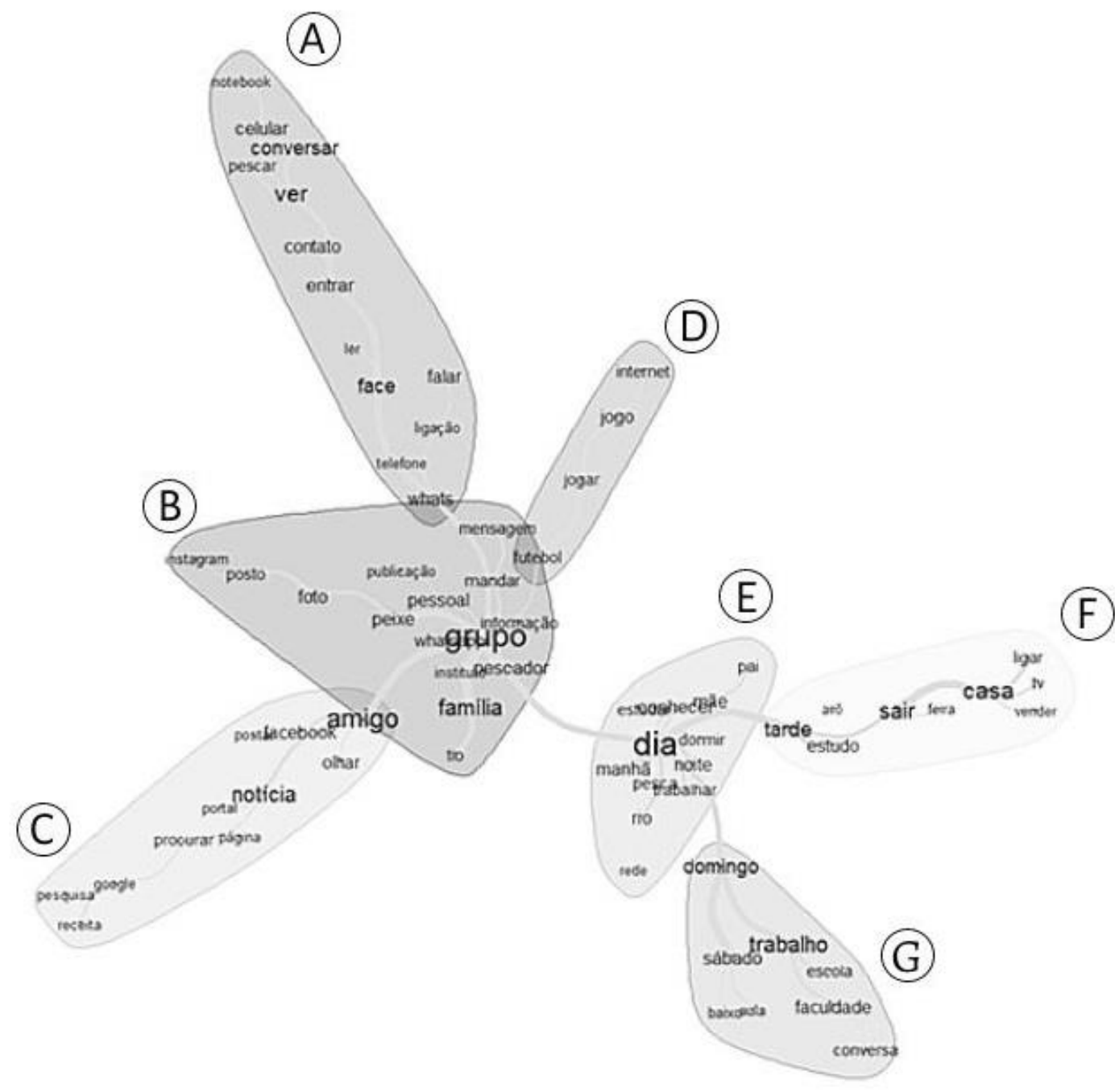

Figura 3: Análise de similitude: jovens de Porto Vera Cruz

Fonte: Elaborado pelos autores

À esquerda da configuração, na nuvem B, que congrega e compartilha elementos com as demais (amigo, whats e futebol), a palavra central grupo, apresenta ligações com termos também evidentes como família, pescador e amigo, identificado pela espessura da linha que os vincula. Isso evidencia os núcleos de sociabilidade dos jovens, que se dão por meio das relações afetivas e profissionais, sendo mediados pelos grupos de whatsapp (nuvem A) e facebook (nuvem $\mathbf{C}$ ).

As demais conexões que vinculam grupo com as nuvens restantes, tendo em vista a espessura das linhas, não são tão significativas, exceto a ligação com o termo dia, já explorada anteriormente. 
O agrupamento $\mathbf{C}$ traz conexão forte entre os termos amigo, notícia e facebook, o que demonstra a importância dessa rede social para o relacionamento de amizade entre os jovens e como fonte de notícias. Também expressa os usos que os jovens fazem do Facebook, revelados pelos termos notícia, olhar e postar.

De forma semelhante, a nuvem $\mathbf{A}$ indica as práticas dos jovens nas redes, em especial WhatsApp e Facebook, expressas pelos termos falar, ler, entrar, contato e conversar. Por outro lado, a relação entre os termos celular, conversar e pescar, indica que a atividade da pesca tem relação com esse dispositivo, tanto para interação entre os pescadores como para anunciar a venda dos peixes.

A intersecção entre as nuvens B e A é evidenciada pelo termo whats, o qual é comum para os dois agrupamentos de palavras. Vinculado aos termos mandar, mensagem $(\mathbf{B})$ e telefone (A), whats indica o uso do aplicativo para o envio de mensagens através do celular, conectando tanto o universo do trabalho quanto o grupo familiar.

A nuvem D, por sua vez, engloba os termos jogar, jogo, internet e futebol, sendo que o último está interseccionado com a nuvem B. A partir da ligação com o referido conjunto, podese interpretar que esta vinculação está relacionada ao uso do grupo de WhatsApp para combinar jogos de futebol através da internet.

Através da representação gráfica (figura 3), observa-se que, em geral, os jovens de Porto Vera Cruz utilizam de forma expressiva os grupos do WhatsApp para trabalho e cultivo dos vínculos afetivos, comunicando-se com família, parceiros de negócios e amigos. Com estes, o Facebook também é importante para comunicarem-se entre si, assim como é utilizado para a obtenção de notícias e pesquisas de outras informações, em especial relacionadas à pesca.

No cotidiano, os jovens trabalham e estudam, em geral, à tarde. Seus finais de semana envolvem lazer, mas também questões de trabalho e estudo. Suas atividades ocorrem em meio ao contexto familiar, mediada pela tecnologia.

\subsection{A importância cotidiana dos amigos: jovens citadinos de Turuçu}

A análise de similitude (figura 4, abaixo) apresenta indicações de conexidade entre os termos amigo, dia, casa, grupo, trabalho, whatsapp, facebook e celular. O tamanho da fonte das palavras indica uma recorrência ligeiramente maior das palavras dia, casa e grupo, o que revela a importância do espaço doméstico e das redes sociais (grupos) no seu cotidiano.

O diagrama tem uma configuração tal que a nuvem $\mathbf{E}$ é central e aglutina todos os agrupamentos da parte superior, a partir das conexões do termo amigo com whatsapp (nuvem 
B) e com grupo (nuvem D), que se conectam com outras nuvens (A e C). Esse encadeamento faz referência aos temas que dizem respeito à relação com as tecnologias, às redes sociais e ao cotidiano.

A partir dos termos amigo, conversar e redes sociais, presentes na nuvem $\mathbf{E}$, pode-se observar que a temática do agrupamento se refere às práticas de sociabilidade por meio das redes sociais. O mesmo assunto está presente na nuvem $\mathbf{B}$, porém descrevendo os nomes das redes: whatsapp, facebook, twitter e instagram. Essa nuvem medeia a $\mathbf{E}$ e a $\mathbf{A}$, mais especificamente os termos celular e amigo, portanto percebe-se que as redes sociais estão diretamente ligadas às relações de sociabilidade entre os jovens e seus grupos de amigos, através do dispositivo móvel.

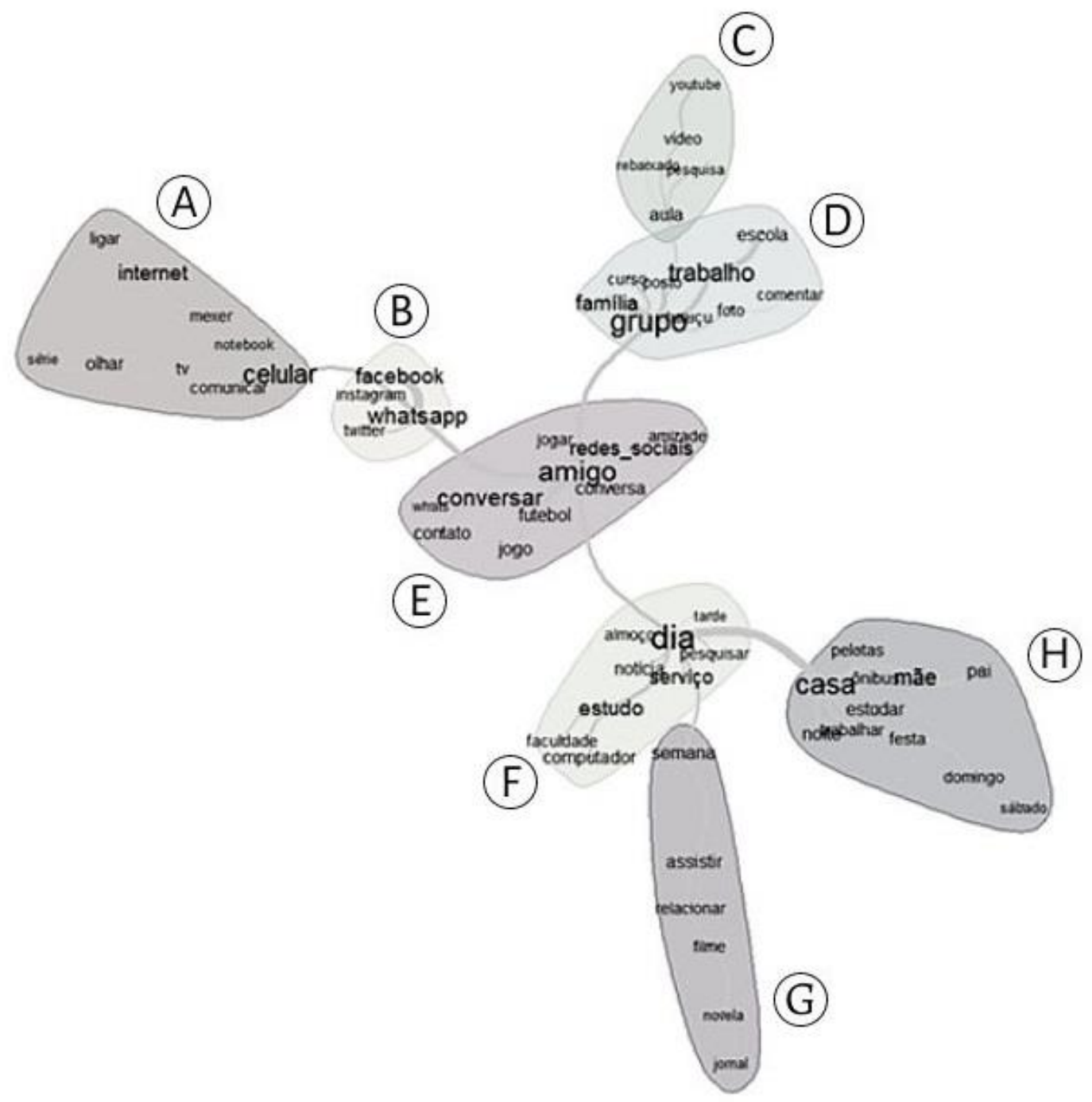

Figura 4: Análise de similitude: jovens de Turuçu

Fonte: Elaborado pelos autores 
A linha que conecta as nuvens A e $\mathbf{B}$ indica fortemente que a sociabilidade dos jovens, mediada pela tecnologia, se desenvolve especialmente via WhatsApp e Facebook, identificada pela espessura da linha que relaciona as duas redes. Isso é reforçado pela ligação dos termos facebook e whatsapp com celular, presente na nuvem $\mathbf{A}$, indicando que as redes são acessadas em especial por este dispositivo.

O conjunto A ainda descreve usos de diferentes meios, como tv e notebook, relacionados aos termos comunicar, ligar, olhar e mexer. No caso do notebook, o termo está conectado com internet, sugerindo seu uso através daquele aparelho. Já na ramificação que abarca $t v$ a presença da palavra série indica o tipo de conteúdo consumido nesse meio.

O conjunto D, por sua vez, destaca a palavra grupo como a mais recorrente. Infere-se que o termo foi utilizado para se referir a grupos de WhatsApp. As outras palavras da nuvem indicam os usos dos grupos ligados à família, trabalho e escola.

A nuvem $\mathbf{C}$ tem uma intersecção com a $\mathbf{D}$, relacionando o mundo do trabalho, da família e da escola, com o âmbito da tecnologia e das práticas relacionadas a elas. As palavras trabalho e escola, ambas do grupo D, tem conexão entre si e com o termo grupo, o que leva a entender que também são perpassadas pelo uso dos grupos de WhatsApp.

Os termos presentes no agrupamento $\mathbf{C}$, como aula, pesquisa, vídeo e youtube, evidenciam que os meios auxiliam nos afazeres escolares. Possivelmente a busca por vídeo aulas no YouTube serve como auxílio para as atividades escolares, sendo tomado com uma atividade de pesquisa.

Ao observar a configuração inferior do diagrama, a nuvem $\mathbf{F}$ apresenta termos relacionados ao cotidiano, em específico à rotina de trabalho e de estudos, como nos termos dia, serviço, estudo. Nesse âmbito, o computador é citado como o dispositivo a partir do qual desenvolvem suas atividades, especialmente as relacionadas ao estudo, pela proximidade com o termo faculdade. O termo notícia, conectado diretamente ao dia, sugere que a busca por conteúdo noticioso seja um fato cotidiano, possivelmente no horário do almoço.

A nuvem $\mathbf{H}$ também está relacionada às atividades rotineiras, particularmente à mobilidade (ônibus, pelotas), a estudar, a trabalhar e ao fim de semana (domingo e sábado), sendo o termo casa o aglutinador dessas práticas. A palavra festa surge como conexão entre os dias do final de semana, exprimindo a atividade de lazer dos jovens quando não estudam ou trabalham. O termo noite, fortemente conectado à casa pode ser destacado como o único 
marcador temporal presente na nuvem $\mathbf{H}$, o que sugere que permanecem do regaço familiar nesse período.

Assim como o agrupamento $\mathbf{H}$, a nuvem $\mathbf{G}$ aborda atividades que permeiam o cotidiano e os finais de semana, porém em especial sobre o lazer e consumo midiático, indicado pelos termos semana, assistir, relacionar e filme. Todas as palavras deste agrupamento se conectam de forma linear, tendo na extremidade inferior as palavras novela e jornal. O vínculo desses dois termos indica que se tratam de programas televisivos que, em geral, são consumidos diariamente. $\mathbf{O}$ agrupamento $\mathbf{G}$ é uma ramificação do termo dia, localizado no agrupamento $\mathbf{F}$, portanto é possível pressupor que os termos desse grupo fazem sentido às atividades rotineiras.

Pela configuração espacial dos conjuntos de palavras, nota-se uma proximidade entre os grupos que envolvem as práticas sobre tecnologias em contraste às práticas cotidianas relacionadas ao ambiente domiciliar. Através dessa representação gráfica (figura 4), observase que, em geral, os jovens de Turuçu utilizam a internet através do celular para acessar diversas redes sociais, em especial o WhatsApp e o Facebook, com a finalidade de conversar com amigos e família através dos grupos.

Os jovens utilizam os dias úteis para os estudos e o trabalho, além do consumo midiático por meio de filmes, novelas e de jornal. Já o fim de semana, é utilizado também para estudar, trabalhar e planejar participação em festas e encontros. As atividades de trabalho, estudo e lazer são permeadas pelo contexto familiar, em termos físicos e relacionais. [O-B]

\section{ALGUMAS CONSIDERAÇÕES SOBRE A VIVÊNCIA RURBANA DOS JOVENS ENTREVISTADOS}

As representações gráficas indicam que as falas dos jovens abordam temáticas semelhantes, porém com algumas especificidades relativas ao lugar onde moram e à profissão que exercem - comércio, serviços, agricultura, pesca. Todas as análises destacam as redes sociais, a partir de seus dispositivos e usos, em especial para relacionamentos com as pessoas que fazem parte da rede de sociabilidade, o que inclui as relativas ao mundo do trabalho.

O WhatsApp aparece como uma importante ferramenta para a comunicação interpessoal, especificamente através dos grupos. Exceto Itati, nas demais cidades os jovens destacam o termo grupo como um dos mais recorrentes, demonstrando sua apropriação para diversos usos. O termo é central nos diagramas referentes a Porto Vera Cruz e Pedras Altas, as duas cidades onde parecem ter maior relevância. 
Quanto ao contexto cotidiano, relativo ao trabalho e aos estudos, é permeado por práticas no âmbito doméstico tanto referente a esse espaço de vivência quanto no que diz respeito aos relacionamentos que se desenvolvem em meio àquelas atividades. $\mathrm{O}$ termo casa surge como um dos mais recorrentes, indicando essa situação, no entanto, só tem centralidade na representação de Itati, dando um ângulo diferenciado na prática dos jovens dessa cidade.

O termo dia, presente em todos os diagramas com maior ou menor destaque, localizado em diferentes grupos de palavras, pode tanto indicar o contex to cotidiano, quanto o período diurno. De qualquer forma, é um marcador temporal que aponta o período onde as atividades acontecem e sua importância na fala dos jovens. Os destaques do termo são apresentados na centralidade do diagrama de Porto Vera Cruz e de Turuçu, reforçando a conclusão sobre as pequenas diferenças que aparecem nas práticas muito semelhantes entre os jovens das quatro cidades.

A cidade de Itati, por exemplo, tem como singularidade a presença de uma cooperativa que nucleia o trabalho e a sociabilidade dos jovens, pois são eles que a administram. Ela é central em suas vidas, pois não é só o local de trabalho, é um modo coletivo de trabalhar.

Pedras Altas, por sua vez, é a única cidade em que houve um conjunto de termos relacionados ao consumo de televisão, emprestando uma especificidade no consumo midiático dos jovens entrevistados nesta cidade.

A atividade da pesca é particular de Porto Vera Cruz, e também é compreendido através da sociabilidade dos jovens em torno dela, assemelhando-se aos jovens de Itati, mas diferenciando-se no aspecto de que se configura como uma prática familiar. Além disso, um conjunto de termos que apresenta a atividade de jogar futebol se manifestou apenas nessa cidade, enfatizado pelos campeonatos que disputam na outra margem do rio Uruguai com times de jovens argentinos.

Quanto à cidade de Turuçu, onde os jovens têm empregos no comércio e setor de serviços, poucos termos tiveram muita recorrência, o que pode indicar uma maior dispersão de temas e uma homogeneidade de práticas. Ainda assim, uma peculiaridade notável é a nuvem que destaca apenas usos de dispositivos relacionados ao contexto do trabalho.

Quanto às análises de similitude - a esfera técnica das considerações aqui apresentadas -, pode-se dizer que elas têm diferentes configurações espaciais em suas representações gráficas, variando no número de agrupamentos e na estrutura gráfica do conjunto. No entanto, ao analisar a distância ou proximidade entre os grupos conforme a temática, é possível perceber um padrão na configuração das nuvens, em que aquelas envolvendo o contexto da sociabilidade 
se apresentam mais distantes daquelas que representam a descrição das tecnologias e suas funções.

Os diagramas partem de núcleos para ramificações mais específicas, em que a centralidade normalmente é expressa por dois agrupamentos fortemente conectados. Alocamse no centro da representação os termos cuja temática envolve marcadores temporais, indicadores de localidade e ações no âmbito do cotidiano.

Essa técnica de análise mostrou-se produtiva para um tratamento detalhado e hierarquizado dos dados das entrevistas realizadas com os jovens. As representações gráficas geradas pelo IRAMUTEQ são uma proposta viável e eficaz, tanto pela gratuidade do software, quanto pela precisão na construção dos diagramas. Estes benefícios tecnológicos garantem uma menor interferência da subjetividade do pesquisador no agrupamento dos termos, além da rapidez no processamento dos dados. Portanto, as nuvens geradas são precisas em suas representações, principalmente em relação às vantagens gráficas - em destaque as linhas e as cores. Esse indicativo quantitativo, entretanto, não dispensa a interpretação do pesquisador à luz dos conceitos que elegeu para nortear a pesquisa, nem os aspectos qualitativos e singulares do conteúdo das entrevistas.

Para terminar, vale pontuar que, mesmo com a redução da interferência do pesquisador no tratamento dos dados para gerar os diagramas, ainda se fez necessário alguns ajustes práticos para melhor adequação da análise. Vícios de linguagem, artigos, verbos com pouca força representativa, entre outros termos com baixa importância semântica, foram retirados do banco de dados que gerou os agrupamentos. Desta forma, a representação se tornou compreensível visualmente, e a descrição dos diagramas pôde ser realizada de forma precisa.

\section{REFERÊNCIAS}

BARBETTA, Pedro Alberto. Estatística aplicada às Ciências Sociais. 5. ed. Florianópolis: Editora da UFSC, 2002.

BONFIL, Guillermo. México Profundo: uma civilização negada. México: Grijalbo, 1989.

CIMADEVILLA, G.; CARNIGLIA, E. Relatos sobre la rurbanidad. Río Cuarto: UNRC, 2009.

CIMADEVILLA, G. La cuestión rurbana: apuntes para una entrada comunicacional. Intercom Revista Brasileira de Ciências da Comunicação, São Paulo, v. 33, n. 2, p. 73-85, jul./dez. 2010. 
IBGE - Instituto Brasileiro de Geografia e Estatística. (2018) Classificação e caracterização dos espaços rurais e urbanos do Brasil: uma primeira aproximação. Rio de Janeiro: IBGE. Coordenação de Geografia, 2018.

JACKS, N.; TOALDO, M.; MARQUES, J. Jovens Rurbanos e Mediações Tecnológicas: práticas e convivências sociais contemporâneas. Cuadernos del CLAEH, año 36, 106, 105-128, 2017.

JACKS, N.; TOALDO, M.; MIRANDA, F. C.; MONTEIRO, M. C. Jovens do "Brasil Profundo": explorações sobre usos tecnológicos e consumo midiático em Tavares (RS). Encontro Anual da Associação Nacional de Programas de Pós-Graduação em Comunicação. São Paulo: Cásper Líbero, 2017.

JACKS, N. et al. Juventude e Consumo Midiático: explorações etnográficas em tempos de convergência. Congresso Brasileiro de Ciências da Comunicação. Curitiba: Universidade Positivo, 2017.

JACKS, N.; TOALDO, M.; MARQUES, J. Jovens Rurbanos: Consumo Midiático no "Brasil Profundo”. Congresso Brasileiro de Ciências da Comunicação. Joinville: Univille, 2018.

JACKS, N.; TOALDO, M.; MARQUES, J. Youth media practices in rurban contexts: aspects of "Brasil Profundo". IN PEREIRA, Cláudia (ed.). Brazilian Youth. Global trends and local perpectives. London. Routledge, 2020.

JACKS, Nilda. Prólogo. In: Kenbel, Claudia; Demarchi, Paola; Galimberti, Silvina. Íconos de la rurbanidad: actores, prensa, tecnologías y políticas de reordenamiento rurbano en tiempos modernos. 1a ed . - Río Cuarto : UniRío Editora, 2020.

MARGULIUS, M.; URRESTI, M. La juventude es más que una palabra. In: Margulis, M. (Org.). La juventud es más que una palabra: ensaios sobre cultura y juventud. Buenos Aires: Biblos, 2008

MARQUES, J.; JACKS, N.; TOALDO, M. Jovens Rurbanos: experiências no sul do Brasil. Congresso Ibero-Americano de Comunicação - IBERCOM. Lisboa: Faculdade de Ciências Humanas da Universidade Católica Portuguesa, 2017

MARQUES, J.; TOALDO, M; JACKS, N. Juventude e consumo midiático em tempos de convergência: algumas observações. Chasqui. Revista Latinoamericana de Comunicación, n. 137, 73-91, dic.-mar, 2017-2018.

MAS, Jean-François. Análisis espacial con R: Usa R como un Sistema de Información Geográfica. European Scientific Institute, 2018.

MOURA, S.R.B. et al. Análise de similitudes dos fatores associados à queda de idosos. Revista Interd. V.8, n.1, p. 167-173. Mar., 2015.

SILVA, Andressa M. B. da; ENUMO, Sônia R. F. Descrição e Análise de uma intervenção psicológica com bailarinos pelo Software IRAMUTEQ. Revista Temas em Psicologia. jun, vol.25, n.2, p.577593, 2017.

SILVA, Maurílio B. O. da. et al. Uma Análise Das "Falas" Dos Turistas, Em Plataformas Online, A Respeito Dos Atributos Valorizados Dos Restaurantes De Bonito, Mato Grosso Do Sul. II EIGEDIM, Naviraí/MS, 2018. 
Nilda Jacks

Doutorado em Ciências da Comunicação pela Universidade de São Paulo (1993). Pós-doutorado em Comunicação na University of Copenhagen (1999) e na Universidad Nacional da Colombia (2006). Professora titular da Universidade Federal do Rio Grande do Sul. Pesquisadora PQ/ CNPq.

Mariangela Machado Toaldo

Doutorado em Comunicação Social pela Pontifícia Universidade Católica do Rio Grande do Sul (2002). Pós-Doutorado em Comunicação na Universidade Federal do Pará (2016) e na Universidade de São Paulo (2016). Professora Associada da Universidade Federal do Rio Grande do Sul.

Danillo dos Santos Lima Formando do curso de Jornalismo pela Fabico/UFRGS. Bolsista voluntário de iniciação científica do Núcleo de Pesquisa Cultura e Recepção Midiática, coordenado por Nilda Jacks.

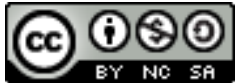

Esta obra está licenciada com uma Licença Creative Commons Atribuição-NãoComercial-CompartilhaIgual 4.0 Internacional 